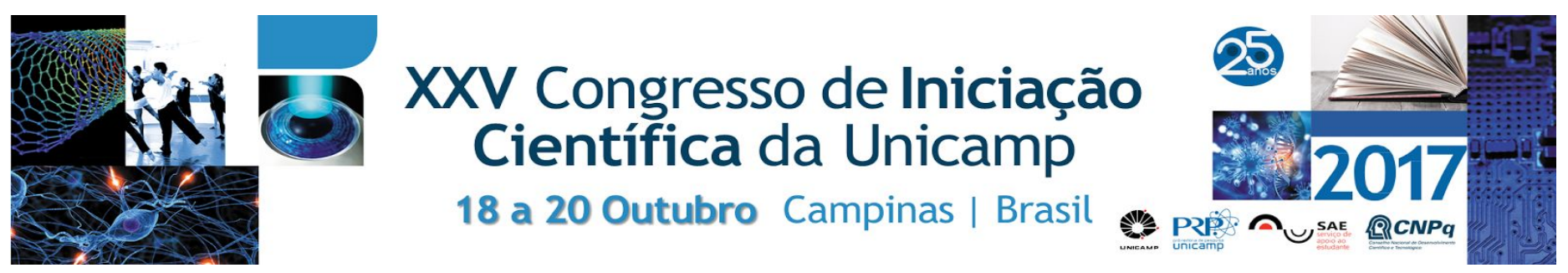

\title{
Introdução ao estudo do desenvolvimento do aprendizado de Matemática
}

\author{
Maria Carolina Ramalho*, Olivaine Santana de Queiroz.
}

\section{Resumo}

Essa pesquisa trata do estudo do livro: "Como Humanos Aprendem a Pensar Matematicamente", escrito por David Tall, no qual ele trabalha quatro pontos essenciais para o aprendizado matemático em todos os níveis de conhecimento: cristalização de conteúdos, incorporação conceitual, simbolismo operacional e formalismo axiomático.

\section{Palavras-chave:}

Pensamento matemático, Met-Before, Estruturas de Conhecimento.

\section{Introdução}

O estudo surge, basicamente, da busca por uma resposta para a seguinte questão: Por que determinados conceitos matemáticos que fazem sentido em um certo contexto, podem se tornar problemáticos em outros? Em resposta, verifica-se que, na busca pela cristalização de conceitos matemáticos, temos três diferentes caminhos (mundos) importantes, pelos quais o pensamento matemático se desenvolve.

\section{Resultados e Discussão}

O desenvolvimento a longo prazo é introduzido, levando em consideração a parte biológica, mental e comportamental do aprendiz, apresentando exemplos dentro da geometria, aritmética e álgebra.

A Abstração Individual é fragmentada em Estrutural, relacionada às propriedades físicas de certo objeto e a Operacional trabalha com operações e padrões que surgem a partir de tais operações. Em um momento posterior, há ainda a junção da abstração estrutural e operacional, que conduzem a abstração formal, que funciona por meio de deduções e definições.

A incorporação do conhecimento é um estágio de grande importância, pois o modo como entendemos e guardamos determinados assuntos afeta diretamente 0 modo como o lembramos em um momento posterior. Havendo neste momento, a divisão entre incorporação conceitual e a incorporação funcional.

Atributos humanos, como a capacidade de receber informações, trabalhá-las e compartilhá-las, são evidenciadas como de extrema importância para a construção de uma estrutura rica do conhecimento. Nesse momento, são introduzidos os símbolos Procepts, que facilitam a representação de processos e conceitos ao mesmo tempo, de forma flexível.

Ao longo da pesquisa, são introduzidos os conceitos de: Set-Before, que faz referência aos atributos naturais que nós humanos temos; $E$ o conceito de Met-Before, que faz referência a experiências que passamos em nossas vidas que afetam nosso pensamento matemático.
Os "Conceitos Cristalinos", são conceitos mentais que devem ter ligações firmes e propriedades inevitáveis (indispensáveis). Cada mundo da matemática, através de situações complicadas, formam seus próprios conceitos cristalinos.

Os três níveis de pensamento consciente: No primeiro nível temos a junção/mistura seletiva, utilizando estruturas neuronais para dar sentido a pequenos conceitos. O segundo é a consciência a curto prazo, que dá origem a um fluxo simples de pensamento. Por fim, o terceiro, é a consciência expandida, que nos permite refletir diversas informações ao mesmo tempo e dar sentido a conceitos mais elaborados e sofisticados.

Para a sofisticação do pensamento, passamos pela Categorização, em que são reconhecidas as propriedades essenciais de figuras ou ações; depois pelo Encapsulamento, que trata da repetição de ações que podem ser simbolizadas e manipuladas mentalmente,terminando com a etapa de Definição, onde hà formulação de conceitos específicos que podem servir de base para raciocínios e provas matemáticas.

No diagrama abaixo, podem ser identificados os três mundos da matemática: Incorporação Conceitual, o Simbolismo Operacional e o Formalismo Axiomático; Seus desenvolvimentos particulares, transições de um mundo para o outro e a estrutura como um todo.

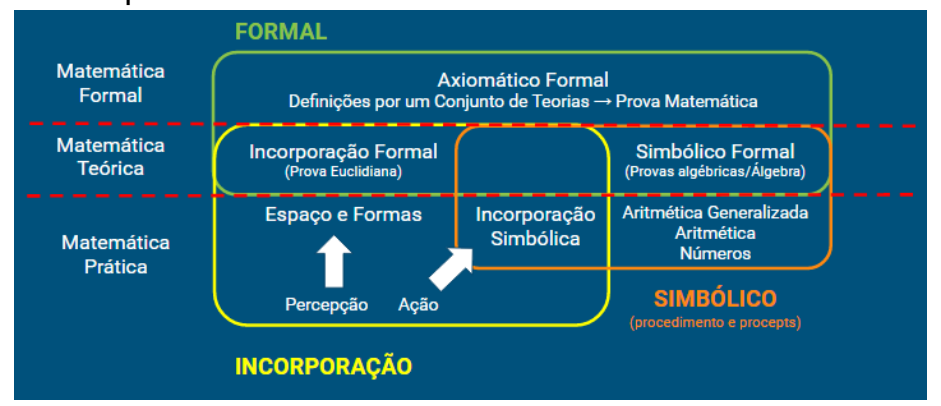

Figura 1. Esquema dos três mundos da matemática

TALL, David. How Humans Learn to think Mathematically. $1^{\text {a }}$ edição. Local: Cambridge, 2013. 